\title{
University freshmen recollect their academic integrity literacy experience during their K-12 years: results of an empirical study
}

\author{
Zakir Hossain(10
}

Correspondence: zakir.researcht|@ gmail.com

ICS Inter-Community School Zurich, Zurich, Switzerland

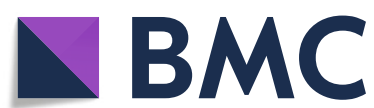

(C) The Author(s). 2022 Open Access This article is licensed under a Creative Commons Attribution 40 International License, which permits use, sharing, adaptation, distribution and reproduction in any medium or format, as long as you give appropriate credit to the original author(s) and the source, provide a link to the Creative Commons licence, and indicate if changes were made. The images or other third party material in this article are included in the article's Creative Commons licence, unless indicated otherwise in a credit line to the material. If material is not included in the article's Creative Commons licence and your intended use is not permitted by statutory regulation or exceeds the permitted use, you will need to obtain permission directly from the copyright holder. To view a copy of this licence, visit http://creativecommons.org/licenses/by/4.0/. The Creative Commons Public Domain Dedication waiver (http://creativecommons.org/publicdomain/zero/1.0/) applies to the data made available in this article, unless otherwise stated in a credit line to the data.
Keywords: Academic integrity, Academic integrity literacy, School librarian, University freshmen, Secondary education, High school, Transition literacy

\section{Introduction}

Academic integrity is an essential part of information literacy (Hossain, 2020), a demonastration of global citizenship (Anwar et al., 2020), and a commitment to six fundamental values: "honesty, trust, fairness, respect, responsibility and courage" (International Center for Academic Integrity [ICAI], 2021, p. 4). It is the "foundation of ethical teaching and learning" (Eaton, 2021) that is in "Compliance with ethical and professional principles, standards, practices and consistent system of values [ ...]" (European Network for Academic Integrity [ENAI], 2018). The International 
Baccalaureate Organization (IBO) (2019), a recognised leader in international K-12 education states, "Academic integrity is a guiding principle in education and a choice to act in a responsible way whereby others can have trust in us as individuals" (p. 3).

Academic Integrity Literacy (AIL) has emerged as a commonplace term similar to other identified twenty-first century literacies, for example, information literacy (IL), digital literacy, media literacy, health literacy, transition literacy, etc., and is deemed an essential transdisciplinary skill to be successful in academic life and beyond. According to Eaton (2019), "Academic integrity literacy is an inseparable combination of values, behaviours, ethical decision-making and skills necessary for academic success" (para. "Definition"). Hossain (2020) defined AIL as "understanding, gaining and exhibiting the connected knowledge, skills and actions towards ethical and responsible use of information in academia and everyday life" (p. 44). It would not be an exaggeration to say AIL is an integral part of academic literacy and an essential component of academic, research and professional success (Eaton, 2019; Hossain, 2020; Shephard, 2015).

AIL necessarily goes beyond the development of citation and referencing skills "to include an explicit understanding of the values that underpin integrity and a conscious commitment to upholding those values" (Eaton, 2019, para. 4). In a similar fashion, Hossain (2020) explained AIL is a complex, interdisciplinary, multidisciplinary and transdisciplinary issue that requires an understanding of academic integrity and the acts considered as academic misconduct. Therefore, it can be said that AIL is not only about adhering to academic ethics or integrity, but also understanding what causes academic malpractice and how to avoid that to uphold academic integrity.

In K-12, particularly in secondary, ${ }^{1}$ students are exposed to research-based writing assignments (Hossain, 2021) that require skills of documentation, synthesise and appropriate attribution through referencing (Vieyra \& Weaver, 2016). In many K-12 schools regardless of geographic locations, these skills are taught as part of the IL skills (Foo et al., 2014; Ngo \& Walton, 2016; Smith, 2016). However, studies (e.g., Morrow, 2018; Tauginiene \& Gaizauskaite, 2018) continuously highlighted that K-12 schools are not doing enough to educate and uphold academic integrity. Tauginienè and Gaižauskaitė (2018) in particular reported the lack of effective integrity management prone to academic misconduct in high school. Hossain (2020) went further and stated that in K-12, there is a lack of clarity around how to align AIL with the pre-existing IL or transition literacy frameworks that each school or district follows, who should teach it and to what extent.

The research also identified various factors impeding AIL education and promotion in the $\mathrm{K}-12$ setting, such as:

i. limited AIL instruction and a lack of standard academic integrity policy in secondary schools (Vieyra \& Weaver, 2016; Hossain, 2020);

ii. minimal plagiarism detection software usage in high schools (Vieyra \& Weaver, 2016);

iii. teachers failing to distinguish between deliberate and accidental plagiarism or to discourage copying sources without attribution at the secondary education level (Accredited Schools Online, 2021);

${ }^{1}$ usually between the ages of 11 and 18 also known as middle school [MS] and high school [HS] 
iv. low-level collaboration between school librarians ${ }^{2}$ and subject teachers in IL

(Davies, 2012; McKeever et al., 2017) and AIL instruction (Hossain, 2020) in K-12, and.

v. lack of direction from K-12 standards, practices and guidelines about what legal (copyright) and ethical literacy should learners master at each grade level, where they are embedded in the curriculum and who should teach these skills (Hossain, 2020).

Studies also promulgated academic malpractice is a growing concern worldwide, starting at the elementary level and continuing through high school, university (Dukes, 2012; Samanta, 2018; Yoannou, 2014) and professional life (Harding et al., 2004). Yoannou (2014) reported plagiarism is "increasingly prevalent at the high school level" (p. 20) and Dukes (2012) hypothesised many high school students believe they can get away with cheating. Many studies indicated that students who are involved in academic malpractice in high school continue to cheat at alarming rates in college (Mulisa \& Ebessa, 2021; Tauginienė \& Gaižauskaitè, 2018) and life beyond academia (DenisovaSchmidt, 2019; Stoesz \& Yudintseva, 2018). Several research papers describe that with inadequate skills of proper source attribution, entering freshmen often struggle to meet the university level writing expectations (Broeckelman-Post, 2009; Vieyra \& Weaver, 2016); and most likely commit academic misconduct (Hossain, 2020; Mulisa \& Ebessa, 2021), both intentionally and unintentionally.

Although studies documented a lack of AIL skills and the rise of academic misconduct in the secondary education stage, particularly in high school, very little is known about students' empirical AIL education experience in their secondary education years. Keeping the aforementioned background in mind, this study was formulated to:

1. Explore students' AIL experience gained in their secondary education years;

2. Identify participant students' self-perceived perceptions on AIL education and their sociocultural views on academic misconduct; and

3. Comprehend course instructors' experience with freshmen and their overall views on students' AIL competence.

\section{Literature review}

High schools help students become university and career-ready (Farmer \& Phamle, 2021). However, there is an existing gap between "what high schools teach and what colleges expect" (Venezia \& Jaeger, 2013, p. 117). Hossain (2020) called this gap "a supply and demand gap" (p. 10) and highlighted AIL education and skills requirements between pre- and post-secondary institutions as an example. Dukes (2012) states the critical complication facing high schools today is a "lack of Academic Integrity among students" (p. 1). Numerous research studies also claim that many high school graduates come from an academic background that hardly prepares them for university level work (Martin et al., 2012; Venezia \& Jaeger, 2013) including developing skills on how to paraphrase and cite (Broeckelman-Post, 2009; Vieyra \& Weaver, 2016) reference

2also known as teacher-librarian, school library media specialist, library teacher and professeurs documentalistes (Hossain, 2019) 
information sources (Gravett \& Kinchin, 2020); understand what is considered to be academic misconduct (Bacha et al., 2012); and, how to avoid plagiarism (King \& Brigham, 2018), among others.

Instructional methods, course design and instructional delivery seem to have a significant influence on students to engage in academic integrity violation or not (Çelik \& Lancaster, 2021; Orosz et al., 2015). Miller and Bartlett (2012) study reported that there is little agreement from teachers and between departments insofar as to which subject/ curriculum information and digital literacies should be taught at the secondary level. This is not an exception in the context of AIL education. Indeed, studies confirmed that in many K-12 schools, there is no formal policy on the ethical use of information (Hossain, 2020) and no one is designated to teach students how to guard against academic malpractice (Beaudry, 2019; Benjes-Small et al., 2008; Hossain, 2020), including whether certain actions might affect the legal dimensions of copyright and ethical use of information.

Research recommends that faculty in Higher Education Institutions (HEI) should reflect on their own practice (Hulsart \& McCarthy, 2009) and how to develop courses that ensure an ethical classroom and assessment climate (Yoannou, 2014) which is equally applicable to K-12 teachers. Blair (2017) and Nawaz (2017), for example, suggest a culturally responsive pedagogy (CRP) when teaching academic integrity to socially marginalised, culturally and linguistically diverse student groups. Menéndez and Valle (2018) recommend that educational systems should embed 'academic honesty' within their curriculums. Eaton (2020) went further by proposing a framework i.e. the $4 \mathrm{M}$ Framework focuses on the teaching and learning discourse of academic integrity in HEI involving all related stakeholders: individual (micro), departmental (meso), institutional (macro) and community (mega). In a similar fashion, Hossain (2020) advocates for a combined AIL instructional approach in K-12 that involves all related stakeholders including students, teachers, library professionals, school administrators and parents.

Students' schooling systems (Khan \& Mulani, 2020), curriculum or standard (Hossain, 2020; Menendez \& Valle, 2018; Thompson et al., 2017) are also significant factors of AIL education and perception. Students' and teachers' culture, political views and religious belief and practices can also influence their propensity to academic integrity (Akbar \& Picard, 2020; Hongwei et al., 2017; Nelson et al., 2017). Cutri et al. (2021) imply that an individual's "decisions and meaning making capacity" (p. 8) can be influenced and guided by their culture. Consequently, a plethora of studies pointed out that cultural barriers and differences put students at greater risk of academic malpractice (Campbell, 2017; Thompson et al., 2017, Velliaris \& Breen, 2016), be it intentionally or unintentionally.

The literature also confirms that library professionals traditionally collaborate with classroom teachers (Wagg \& McKinney, 2020) and offer instructional support on IL and AIL, such as information searching, evaluation, citation, referencing and plagiarism awareness (Farmer \& Phamle, 2021; Gavigan, 2021; Hossain, 2020); how to correctly employ a certain convention and bibliographic management software (Benjes-Small et al., 2008; Morrow, 2018; Vieyra \& Weaver, 2016). Similarly, in K-12, school library professionals (SLPs) are 'instructional partners' of teachers who work collaboratively to meet curriculum and IL goals (Kammer \& Hays, 2021; Toerien \& Harrow, 2019 cited 
in Wagg \& McKinney, 2020). Numerous studies have highlighted how SLPs develop the IL, transition literacy and other transdisciplinary skills of students whilst in K-12 (Smith, 2016; Streatfield et al., 2011; Wagg \& McKinney, 2020), endorsing SLPs as the core members of the IL team for developing and implementing ethical education (Hossain, 2020; Williamson \& McGregor, 2011) under the existing IL/transition literacy curriculum. Gavigan (2021) highlighted that SLPs collaborate with teachers to guide students to "understand the ethical use of ideas and information" including "acknowledging authorship and properly citing content" (para. 3) that builds students' knowledge on ethical decision-making.

Studies further reported partnerships and outreach programming between secondary and post-secondary librarians and libraries in the USA (Cameron et al., 2019), Canada (Buchansky, 2021; King \& Brigham, 2018, Morrow, 2018) and in the UK (Wagg \& McKinney, 2020) aiming to develop IL and AIL skills to prepare students for a smoother transition to university. Saunders et al. (2017) in their study emphasized "a need for better communication and coordination" (p. 282) between librarians in high schools and HEI to prepare students for their transition to university. For example, Nichols et al. (2005) suggest "K-20 information literacy" (p. 75) and Beaudry (2019) advocates for a "Transition Literacy" initiative to connect the two stakeholders e.g., K-12 and HEI. Studies such as those by Carr and Rockman (2003), Burhanna and Jensen (2006), and Beaudry (2019) further recommended dialogue between K-12 school and HEI librarians and encouraged librarians to collaborate on enabling students to succeed both in $\mathrm{K}-12$ and HEI.

Much of the research mentioned above provides evidence insofar as the lack of AIL knowledge and experience high school graduates have upon enrolling in universitylevel courses and how they find the AIL application concept difficult to understand, which leads to the significance of investigating students' empirical AIL education experience in their K-12 years, particularly at the secondary level. Despite the significance and clear implications, students' AIL education experience during their primary and secondary education stages has never been highlighted in the research, either in HEI or $\mathrm{K}-12$. From this viewpoint, this study was formulated to address the literature gap, exploring the AIL education experience of university freshmen in their K-12 years. This has significant implications on pre-and post-secondary education institutions in improving the attitudes and the quality of AIL education and the instructional support students may need.

\section{Research methods}

This study was an applied research project that was part of a Masters of Education degree and used a mixed-methods exploratory approach to comprehensively explore, on the one hand, the university freshmen's AIL education experiences during their K-12 years and their personal views on AIL education. On the other hand, it also investigates the university course instructors' perceptions about their students' AIL competence brought from K-12. Research such as Johnson et al. (2007) and Schoonenboom and Johnson (2017) suggested that mixed methods research is effective in understanding a phenomenon in-depth and breadth that requires attention from all related aspects. 
The target population of this study was students enrolled in an online university ${ }^{3}$ Foundation Course (FC) in 2020 (Term 3, July) and the course instructors. Foundation courses are pre-degree courses required to enroll in an undergraduate degree programme at a selected university. In their first term, newly admitted students are placed in two courses: 'Online Education Strategies' and an additional course related to their major studies. According to the admission requirements of the university, the participants should have completed a high school diploma/certificate or equivalent and be at least 18 years old. The surveyed university markets itself as the first non-profit, US accredited, tuition-free, online university. With nearly 106,000 students from 200 countries and territories, most of its students are working adults, young parents, and refugees or undocumented students. Since the university is inclusive and not selective in who enrolls, students arrive from various sociocultural and educational backgrounds.

\section{Data-collection instruments}

For this study, two separate instruments for students and instructors were developed based on the outcomes of the literature review and professional experience. For students, the survey questionnaire was prepared using Google Forms and for instructors, a structured interview method was followed using open and close-ended questions. The questionnaires and the prescribed 'Research Ethics Form' were submitted to the university IRB (Institutional Review Board) for approval. After IRB's approval, the research instruments were forwarded to the university's 'Assistant Instructional Designer' to serve as a point of contact between the researcher and the survey participants. In accordance with the university's ethics guidelines, at the beginning of the survey, potential participants were informed about the purpose of the study, data privacy and provided with the contact information for the research supervisor and the researcher. Finally, the 'point of contact' shared the survey questionnaires with the target populations, and the responses were automatically recorded and tabulated in Google Forms and Google Docs. The data were then procured in spreadsheets and analysed using SPSS Statistics Version 26.

The student questionnaire consisted of three sections with closed, semi-open (utilising a 5-point Likert scale), and open-ended questions. The first section, titled 'Secondary School Experience' required respondents to rate their AIL experience in middle and high schools, specifically familiarity with citation and referencing, plagiarism and who taught them AIL. The second section focused on students' experiences with the current university, such as familiarity with the university's academic integrity policy and procedures, AIL requirements, and to what extent students received support from the university and instructors. Finally, section three gathered demographic information, including students' sociocultural perspective on academic integrity or ethical use of information. For this paper, data received for the first and third sections were included and analysed.

The instructors' structured interview questionnaire, on the other hand, employed eight questions focusing mainly on four themes, such as their perceptions of students' AIL skills, instructional strategies for AIL promotion and implementation in their contexts, experience with students' academic misconduct reporting procedures, and 
available AIL resources and support for students and instructors from the university. The qualitative data collected from instructors was analysed using thematic analysis and to keep aligned with the aims of this paper, the first two themes e.g., instructors' perceptions of freshmen AIL skills and instructional strategies for AIL teaching and promotion were included. Instructor responses $(n=14)$ were labeled F1 to F14 based on their participation date and time, the earliest respondent being F1 and the latest, F14. There were no demographic questions on the instructors' questionnaire. For this study, quantitative results were triangulated with qualitative interviews to establish reliability (Creswell, 2003) and "convergence, corroboration and correspondence" (Greene et al., 1989, p. 259) of findings from quantitative and qualitative methods. Additionally, in-depth desk research was conducted to consult the related literature and reports.

\section{Demographics (students)}

Demographic data such as participants' age, geographic locations, countries where they completed secondary education, high school diploma/certificate awarding authorities and the sociocultural backdrop of participants provided a useful context for this study.

From the students' survey, 431 responses were received that represented 75 countries ( $n=405$, as some selected 'not prefer to say') across all geographic regions (see Table 1), with the United States (102) being the top participating country, followed by Nigeria (64), Kenya (19), Ghana (12) and Saudi Arabia (11).

Regarding gender $(n=431), 56.4 \%$ of participants were male, $40.6 \%$ female and the remaining (3\%) participants preferred not to disclose their gender identity. With respect to age $(n=428)$, survey respondents were scattered across all age groups, with the largest group falling in the range between 23 and 27 years details in Table 2.

Considering the highest level of education participating students achieved $(n=431)$, the majority completed a high school diploma/certificate, followed by an associate, undergraduate or postgraduate degree. Insofar as the high school diploma/certificate awarding authorities, the larger part received their high school diploma/certificate locally from their national education systems/education boards, followed by the UK A levels and IB diploma presented in Table 3. Only one student completed their high school certification online and $11.8 \%$ of students answered "not sure" with regard to their high school diploma/certificate providers.

Table 1 Participants' by World Bank ${ }^{*}$ classified geographic regions $(n=405)$

\begin{tabular}{llll}
\hline Region & $\begin{array}{l}\text { Number of } \\
\text { respondents }\end{array}$ & Percentage & $\begin{array}{l}\text { Number of countries respondents } \\
\text { from }\end{array}$ \\
\hline East Asia and Pacific & 30 & 7.4 & 11 \\
Europe and Central Asia & 27 & 6.7 & 13 \\
Latin America \& the & 23 & 5.7 & 13 \\
Caribbean & & & \\
Middle East and North Africa & 39 & 9.6 & 12 \\
North America & 107 & 26.4 & 2 \\
South Asia & 24 & 5.9 & 6 \\
Sub-Saharan Africa & 155 & 38.3 & 18 \\
Total & 405 & 100 & 75 \\
\hline
\end{tabular}

*https://datatopics.worldbank.org/world-development-indicators/images/figures-png/world-by-region-map.pdf 
Table 2 Participants' age and gender $(n=428)$

\begin{tabular}{|c|c|c|c|c|c|c|c|c|}
\hline \multirow[t]{2}{*}{ Gender $(n=428)$} & \multicolumn{7}{|c|}{ Age groups $(n=428)$} & \multirow{2}{*}{$\begin{array}{l}\text { Total } \\
\text { (\%) }\end{array}$} \\
\hline & $18-22$ & $23-27$ & $28-32$ & $33-37$ & $38-42$ & $43-47$ & $\geq \mathbf{5 0}$ & \\
\hline Male & 34 & 55 & 48 & 41 & 27 & 17 & 19 & $241(56.4)$ \\
\hline Female & 28 & 35 & 28 & 28 & 25 & 12 & 18 & $174(40.6)$ \\
\hline Prefer not to say & 2 & 2 & 2 & 1 & 4 & 1 & 1 & $13(3)$ \\
\hline Total (\%) & $64(15)$ & $92(21.5)$ & 78 (18.2) & $70(16.4)$ & $56(13.1)$ & $30(7)$ & $38(8.9)$ & \\
\hline
\end{tabular}

Note: Three students ( 1 male and 2 females) did not select their age groups

Findings

The findings of the study are divided into two target populations: students and instructors.

\section{Students' familiarity with AIL}

The majority of the participant students (43.6\%) reported they became familiar with AIL when they commenced their Foundation Courses with the selected university. Respondents data also indicated that during their secondary education years, roughly 1 in 10 in middle school (9.3\%) and 1 in 5 high school (20\%) received AIL education, such as citation and referencing skills. Nearly a quarter of them received AIL education whilst doing their bachelor's degrees. About half of them reported they have been familiar with plagiarism (causes and consequences) since their secondary education level as the data depicts in Fig. 1. A small portion of students, however, indicated they were 'Not sure' about how to cite and reference a source and what is considered plagiarism and further data analysis confirmed their highest education is a high school diploma/certificate.

It was pertinent to know who teaches or instructs AIL in secondary. A majority of students reported 'no one' educated them about citation and referencing (61.4\%), and

Table 3 Participants' high school (HS) curriculum providers vs. highest education received ( $n=431)$

\begin{tabular}{ll}
\hline Education and HS Curriculum & Participants (\%) \\
\hline Highest Education ( $\boldsymbol{n}=\mathbf{4 3 1}$ ) & \\
High School & $282(65.4)$ \\
Associate Degree (2-year programmes) & $30(7.0)$ \\
Undergraduate (BA or equivalent) & $96(22.3)$ \\
Postgraduate (MA or equivalent) & $23(5.3)$ \\
HS Curriculum ( $\boldsymbol{n}=\mathbf{4 3 1})$ & \\
A Level & $41(9.5)$ \\
Cambridge IGCSE & $15(3.5)$ \\
Edexcel & $3(0.6)$ \\
English National Curriculum (UK) & $13(3.0)$ \\
IB Diploma & $21(4.9)$ \\
National Curriculum (of my country) & $200(46.4)$ \\
US National Curriculum & $86(20.0)$ \\
Not sure & $52(12.1)$ \\
\hline
\end{tabular}




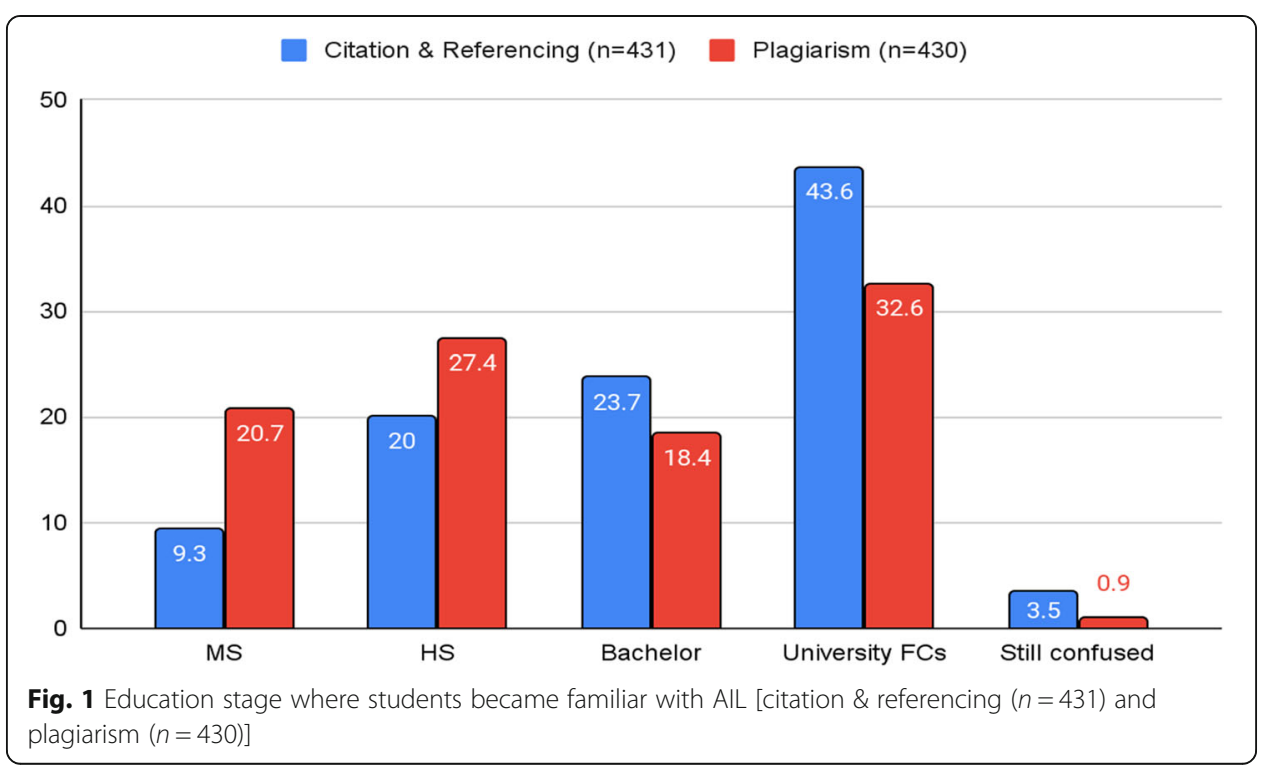

issues of plagiarism $(54.7 \%)$ in secondary school. However, the remaining students acknowledged that their teachers and SLPs instructed them in AIL skills in secondary as illustrated in Fig. 2.

\section{Students' personal and sociocultural perspectives on AIL and AlL education}

To explore students' personal and sociocultural views on academic integrity and academic malpractice-related issues, the following questions were posed:

- To what extent do you agree/disagree with the statement: "Plagiarism/academic cheating is considered unethical in my culture"?

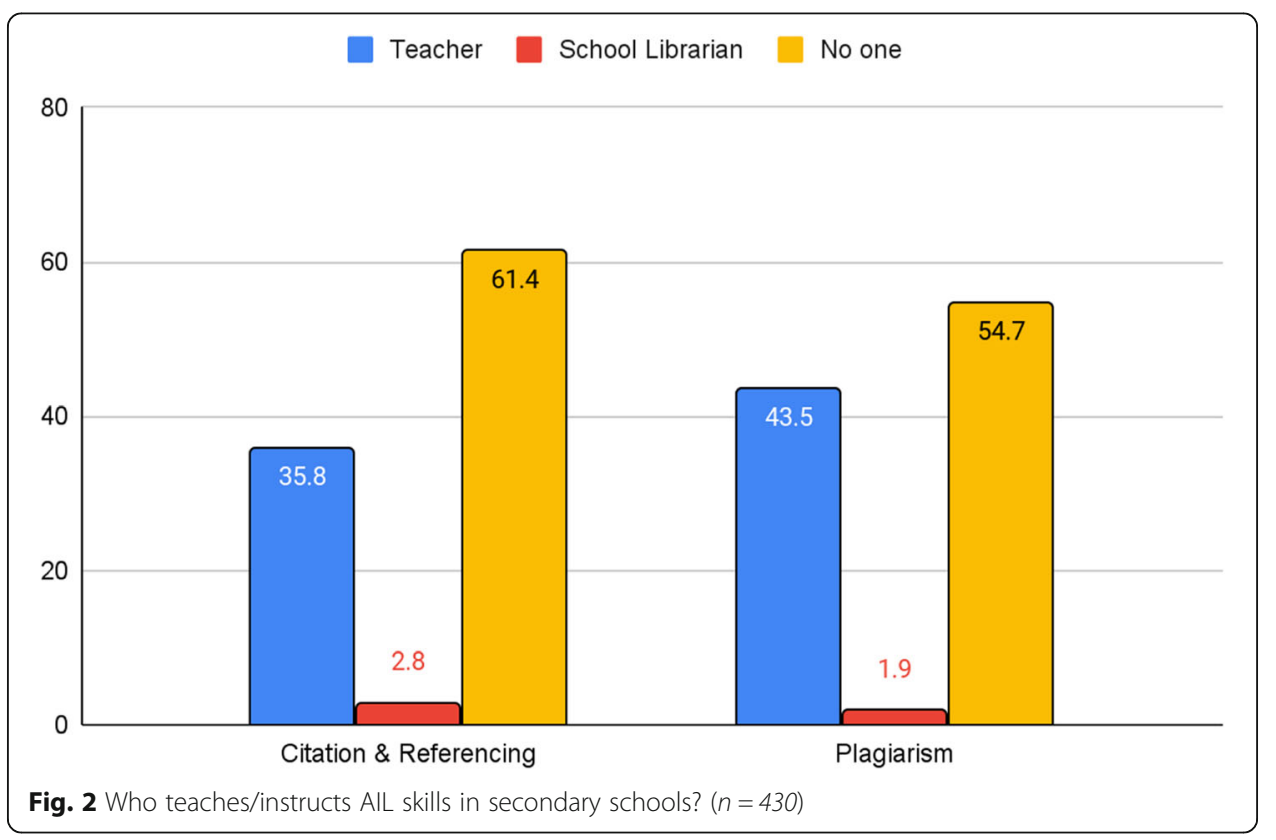




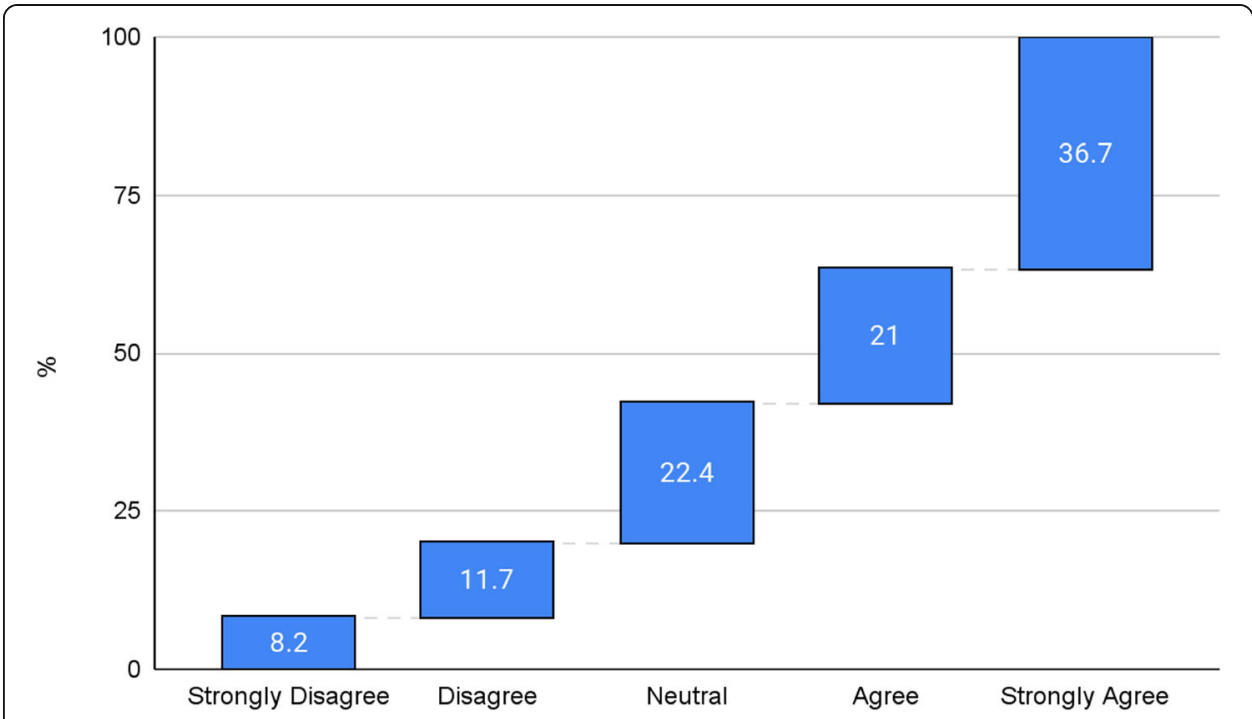

Fig. 3 Students' opinions on the prompt "Plagiarism/academic cheating is considered unethical in my culture" ( $n=428)$

- At what level of education should AIL education e.g., citation and referencing skills be introduced and strictly followed?

Regarding the statement "Plagiarism/academic cheating is considered unethical in my culture", the responses were scattered across a 5-point Likert scale as depicted in Fig. 3. It was discouraging to learn that more than a quarter of the participants tend to indicate plagiarism or any other academic malpractice is not considered an unethical action in their cultures. Remarkably, almost one-fourth (22.4\%) of participants held a 'neutral' position in this regard. Could it be implied that academic misconduct is not a relevant concern in their contexts?

To develop individual views on ethical usage of information such as AIL education, what would be the appropriate education stage to introduce AIL. This study considered this prompt and attempted to comprehend students' views. As illustrated in Fig. 4, the majority of the survey participants opined that citation and referencing skills should be introduced and be strictly followed in secondary, and a small number of them, however, reckoned that it could be ushered in as early as primary. Although just over one-third of participants suggested that these skills should be introduced at middle school (MS) ${ }^{4}$ level, only $13 \%$ agreed that they should be strictly adhered to at this stage of education.

\section{Findings from the instructors' survey $(n=14)$}

Course instructors' perceptions about their students' AIL competence is a valuable aspect of this study. As explained in the methodology section, the data collected from the instructors were analysed under four thematic groups and this paper incorporated the first two themes as they are relevant to this paper's aims and scope.

${ }^{4}$ Ages between 10-15 (Grade 5/6 to Grade 9/10) depending on education/curriculumn system. 


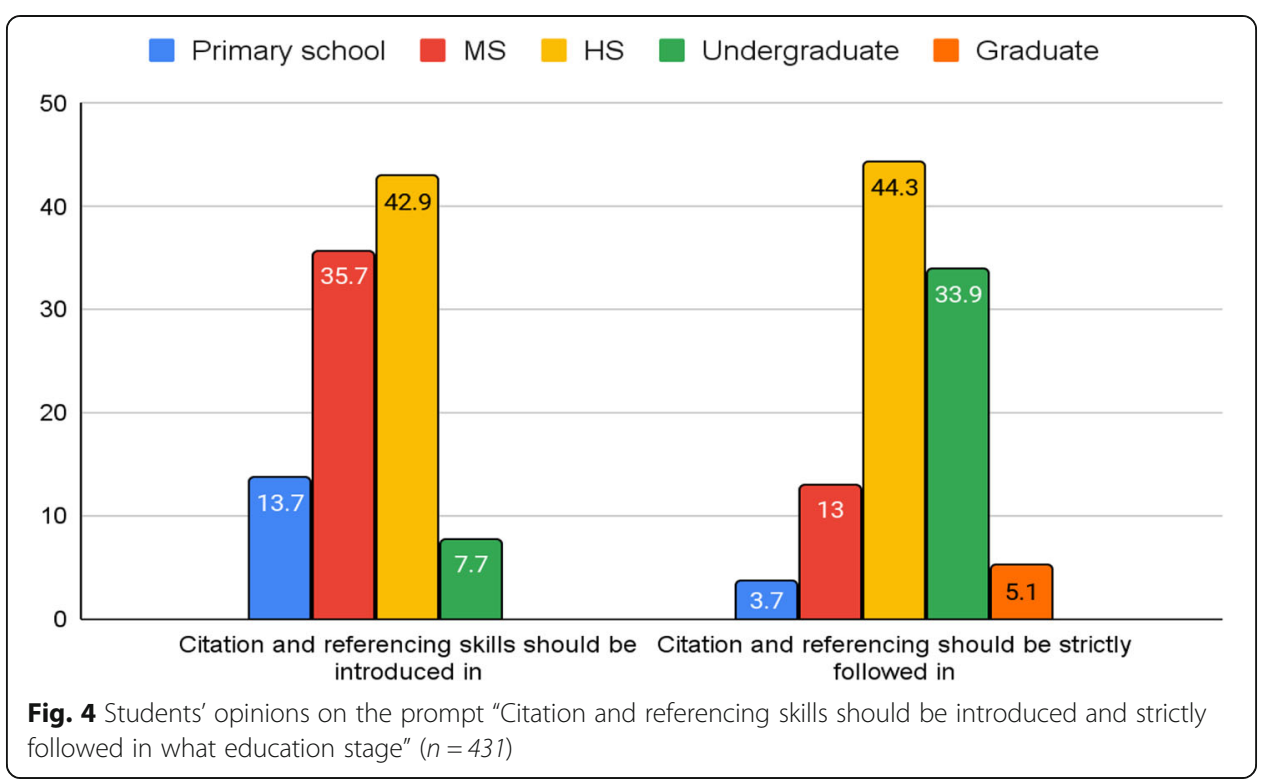

Instructors' opinions on freshmen's AIL competence When instructors were asked to evaluate their FC students' competence on AIL, it was found that most of the instructors agreed that a good number of students (see comments from F2, F5, F7-12) are familiar with AIL and understand the related issues including consequences of academic misconduct. However, instructors also expressed that the vast majority of students fail to put their knowledge into practice as to how to cite properly and reference information using the university required citation convention e.g., APA (American Psychological Association). For instance, instructor F2 mentioned that:

"A few students appear completely oblivious to academic integrity and what plagiarism is (approx. 15\%). Most students understand but fail to properly cite information (approx. 60\%). Most of these students usually make adequate progress throughout the course and have a better understanding by the end of the term. The remaining students seem to have a solid grasp of academic integrity and how to avoid plagiarism (approx. 25\%)."

From a similar stance instructor F7 shared:

"I would say that the majority do [understand academic integrity concepts], but also may struggle to learn and utilize appropriate citations and references (may do one but not the other, not cite paraphrased info, not format appropriately). I would say $95 \%$ understand the meaning of academic integrity, whether they are perfect at executing it or not."

Instructor F5 commented constructively that:

"As a long time Online Instructor at the University that first developed online education, I can say [university] students are no different as are all my other students 
when it comes to demonstrating understanding of academic integrity. Errors are still made, and sometimes students are very slow to make [a] change."

Instructors F7-12 and F13 were quite concerned about FC students' AIL capacity and extended that more than half of the participant freshmen lacked comprehensive AIL competence.

F7 "I do not believe they understand [AIL]. I believe there are a lot of issues with language barriers, and a lot of my students are struggling to form complete sentences. I would say $50 \%$ understand the meaning."

F9 "I think its [it's] one aspect of reading the material and another to understand. About 60\% understand [AIL]. I think the more exposure the better."

F10 "I think they understand [AIL] as much as their grasp of English will allow. To a large extent at $70 \% . "$

F12 "Students are prepared (50\%) but still require guidance."

F13 "No, I do not. Most students are unaware of [AIL] this 70\%"

\section{AIL instructional/promotional approaches that effectively work for the instructors}

A few questions addressed instructors' teaching and communication approaches on AIL and related issues, such as introducing the AIL topics, the strategies they follow for positive reinforcement, specific tools or methods as most/least effective, etc. Three of the instructors [F7, F9 \& F11] had yet to find any specific tool that could be effective in coaching AIL in an online teaching environment. Others shared their views presented in Table 4.

Table 4. Successful instructional strategies and effective methods/tools for AIL education.

\section{Discussion}

The results from the student survey demonstrate that a vast majority of freshmen, regardless of age, geographic location and the characteristics of the participating community, had poor AIL education experience in their K-12 years, which suggests a more contextual, connected and interdisciplinary AIL education is needed in K-12. To build an academic integrity culture at an early education stage, it is essential to put emphasis on an interdisciplinary instructional approach as no single department or educator e.g., teacher/teacher-librarian can offer rigorous AIL education support. To ensure AIL education happens in the classroom, K-12 schools should have AIL policies and procedures, instructional models, related resources and professional development for educators perhaps led by qualified SLPs. Most importantly, to establish a culture of academic integrity in $\mathrm{K}-12$, institutions need to involve all related stakeholders, including parents.

Another significant concern raised by this study is the 'continued disregard' of the value of AIL education in K-12 years as justified by the various participants of this study, no matter what their age, geographic location, or educational background. Bucher (2000) claims that the lack of IL or AIL awareness [referred to as 'Library Skills' 


\section{Appendix}

Table 4 Successful instructional strategies and effective methods/tools for AlL education

AIL topics introduction and reinforcement strategies

[F2] I post a section in the Welcome Announcement that explains APA and violations for committing academic integrity. I also have an "APA Help" thread posted in the Course Forum that I encourage students to utilize throughout the term. The thread also contains additional resources. Moreover, I make an effort to explicitly explain and show where in students responses there are issues with APA and, potentially, plagiarism.

[F4] I mention the University's stance on academic integrity, and I also provide links to APA citation handbooks. Additionally, I use unicheck [UniCheck] to identify any issues and bring them to light to the students.

[F5] I post a message in the Course Forum and in Announcements prior to the start of the course; I provide information and coaching about using two tools that I discuss to help students with Academic Writing and with APA Citation and Sourcing issues.

[F9] I let students know that the expectation is that they begin to practice and attempt to use APA citations and references from the beginning and that we will keep working on them throughout the term. The first week I will correct with a written warning, the second week I will correct with a written warning for things that have at least a reference OR a citation, for neither I will report. Week 3 is when the course material goes over this information, so after that, I will correct errors as long as there is a real effort, but [the] majority of cases get reported with a formal warning. The first week I also make a post in the announcement section with direct links to resources like the UoPeople cheat sheet and Purdue OWL website. Second week, I post an example paper of my own making that highlights how it should look in a paper. Ongoing announcements often discuss avoiding plagiarism as needed.

[F10] 1. I post about the APA format and the importance of it in my introductory course forum post; 2. I review discussion posts and send private messages to students with resources to support them; 3. At about mid-course, I provide a more robust tutorial on APA format through the course forum.
Specific tool or method as most/least effective to teach/promote AIL

[F1] It mostly requires an individual approach to address specific issues relative [to] that student's assignment. The more personalized I make my feedback, as opposed to generic APA comments, the more positive results I see. Also, I think it is of utmost importance to not shame students; I inform them that mistakes happen, and I am here to help them overcome those mistakes so they can find success in their future classes and, ultimately, careers.

[F2] I always tell students to do all their writing (papers, learning journal entries, and even discussion question answers using MS Word. That way, they can use the built-in Spelling and Grammar Checker; it is the best tool of any out there. The settings can be adjusted to catch all potential [potential] errors in mechanics, and that includes formatting of citation or references.

[F3] Positive Reinforcement helps a lot with good writing. I believe the Unicheck system is great, particularly since the discussion forms are automatically assessed with Unicheck. That allows me to tackle the situation immediately.

[F4] Almost weekly I am making announcements to the students on issues I find with their work (mainly citation issues). I also make myself completely available to answer any questions or concerns.

[F6] For most students I have found a warning and a " 0 " on that assignment to be the most effective way to promote academic integrity.

[F8] I find that providing lots of examples and constant correction to be the most effective.

[F10] Practice:) Allowing students to practice and get this wrong, but also being there to support them to get it right the next time. This takes a significant amount of my time teaching- about $45 \%$.

[F12] I reiterate the [university] academic integrity policy and continue to stress it throughout the term. [F14] I encourage students to avoid plagiarism by providing an examples [example] of proper citations[.]

in some K-12 schools] in MS is "particularly unfortunate" as some educators assume that it is not required that students be formally assessed, or receive a grade in the IL or library skills curriculum, and therefore, disregard the essentials of library skills or IL lessons of which AIL is a component.

Students' responses also illustrate that plagiarism or consequences of academic violations receive more attention in secondary schools (see Fig. 3) than focus on a holistic AIL education that emphasises conceptual and contextual learning of AIL. The latter statement is consistent with previous study findings such as Mackay (2021) and Crawshaw (2015, as cited in Tauginienè \& Gaižauskaitè, 2018). In addition, the results from this study indicate that in many schools, SLPs were not well associated with AIL 
instructional support (see Fig. 2). There might be a number of reasons for this, for example, there are no qualified SLPs in those schools; subject teachers/school administrators are not aware of the value and AIL expertise SLPs may have/bring to the classroom, or many of these issues might overlap.

Moreover, data received from the instructors pronounced that participating students have partial AIL knowledge, such as what is considered to be plagiarism and the rationale for acknowledging information sources in academia. However, students are comparatively less proficient in the consolidated application of AIL skills such as understanding the critical aspects of plagiarism; consistent application of a specific referencing convention and the quality of in-text source attribution. Similar results were documented in a previous study (Newton, 2016) that reported newly enrolled UK undergraduate students rated themselves as confident about referencing and plagiarism, but their confidence was misplaced when they encountered critical issues of referencing and plagiarism. This implies that AIL should view as an interdisciplinary component of IL or transition literacy and should be taught across the subjects and grade levels in K12 under a common ethical education framework or model to prepare for college/university. Instructors' feedback also implies adhering to positive reinforcement such as providing related resources, posting messages on the learning management system (LMS) forum and offering personalised feedback improves students' AIL comprehension.

\section{Implications}

Based on the study results, two major implications can be drawn to the attention of K12 institutions. Firstly, K-12 institutions need to build an ethical education system and include AIL education in their curriculums. It could be under the existing IL/transition literacy instructional framework that many schools follow or a separate AIL education model in parallel with IL/transition literacy or an academic skills/research skills support system. To build an academic integrity culture in K-12 at an early age, there might not be any 'one-size-fits-all' or 'short-cut' formulas, but rather a robust AIL education policy and instructional model that is in tune with the dynamic and shifting nature of today's students and the educational institutions they attend. The findings of the study also propose that AIL should be regarded as an integral part of K-12 education and regarded as a transdisciplinary transferable literacy skill for college readiness. This instruction can be started as early as primary school, strengthened during the middle school years, and then further cemented at high school across all subjects to ensure a solid foundation prior to commencing tertiary education.

Secondly, subject teacher and SLPs collaboration, including parent involvement, should be encouraged in K-12. This would result in capacity building and the promotion of the ethical use of information and is considered to be a more authentic and effective approach (Gavigan, 2021; Hossain, 2020; Kammer \& Hays, 2021). To focus on conceptual and functional aspects of academic integrity, teachers in K-12 may need related professional development to hone their AIL competence and instructional skills and school administration should arrange such opportunities. Although school settings and instructional approaches differ from school to school and teacher to teacher, it is 
suggested that education should be the primary consideration insofar as the consequences of academic integrity violation.

In addition to the above, regarding the AIL education gaps between K-12 and HEI, the research clearly identified that creating an academic integrity culture needs the active involvement of all related stakeholders. It would seem to the researcher that a better solution would be that HEI defines what AIL skills are required by students prior to commencing post-secondary education. From there, K-12 educators would have a clearer direction to integrate AIL education and grade level expectations into their standards/curriculums, in order to ensure students graduate with the necessary competence. Collaboration between librarians and/or those responsible for curriculum and lesson planning at both K-12 and tertiary education institutions could strengthen this. Considering the significance of such collaboration between the two stakeholders, it is suggested that HEI should organise AIL outreach in the form of transition literacy or IL development initiatives in K-12 schools.

\section{Conclusion}

This article presents empirical evidence of AIL education in K-12, particularly at the secondary education level. The results of this study argue that many students did not receive proper AIL education in their K-12 years, regardless of their geographic location or schooling backgrounds. Based on the study results, the author suggested that K-12 institutions need to take up the mantle of bringing AIL education to their students through policy development and instructional inclusion rather than leaving the task to students' own endeavours or to HEI. AIL education should be introduced at an early education stage and nurtured throughout middle and high schools. Since in many institutions SLPs are at the forefront of IL or transition literacy education, the potential for subject teacher and SLPs collaboration regarding AIL education and policy development could be better exploited in $\mathrm{K}-12$. This study is only a small window into the very large issue of AIL education, revealing some deep-rooted problems directly connected to the K-12 education system. Nonetheless, the study opens up the dialogue of AIL education and related issues both in secondary and postsecondary educational settings and what role each related stakeholder should play to produce academic integrity literate graduates.

\section{Limitations and future research}

While this study presents students' AIL education experiences during their K-12 years; the significance of formulating rigorous AIL education in K-12 and the power of collaboration among related stakeholders, caution should be taken when drawing conclusions from the findings. The study questionnaire asks students to think back to their secondary school years AIL education experience, which can be limiting in terms of age, memory and what they did not pay attention to when they were in secondary school. Another limitation to consider is that the study did not include K-12 educators, thus data received from students represent only a partial narrative of AIL education in K-12. Finally, the present study was confined to the data of a single institution and to a particular group of students, which may have a profound impact on the collected data. 
Future studies should, therefore, involve K-12 educators (e.g., SLPs, classroom teachers, heads of departments, principals) and freshmen from various universities and focus on the utilisation of qualitative data collection methods. Studies should also attempt to build an indepth understanding of the curriculums of individual countries or geographic regions, and identify the AIL policies or systems that work best in K-12 settings. With this knowledge better options may be developed around the world to promote and execute AIL education across K-12 and ensure preparedness for higher education and career.

\section{Abbreviations}

AlL: Academic Integrity Literacy; CRP: Culturally Responsive Pedagogy; FC: Foundation Course; ENAI: European Network for Academic Integrity; HEl: Higher Education Institutions; HS: High School; ICAl: International Center for Academic Integrity; K-12: Kindergarten to Grade 12; MS: Middle School; SLPS: School Library Professionals

\section{Acknowledgements}

I am thankful to the survey participant students and instructors for their engagement. I am very grateful to Corinne Hertel, Özgür Çelik, Konstantina Martzoukou and Yasmine Aslam for their continued support and encouragement.

\section{Author's contributions}

Full. The author read and approved the final manuscript.

\section{Author's information}

Zakir Hossain is a Teacher-Librarian, spirited researcher and an advocate of school librarianship. He enjoys research, networking and sharing experiences about school librarianship on social media and through publications. As an early career researcher, Zakir's research interests revolve around the field of school librarianship, information literacy particularly copyright and academic integrity literacy. Zakir is based in Switzerland at the Inter-Community School Zurich but calls Bangladesh home.

\section{Funding}

There was no funding for the study.

Availability of data and materials

All data is available upon request.

\section{Declarations}

\section{Competing interests}

No competing interests.

Received: 6 May 2021 Accepted: 2 December 2021

Published online: 15 February 2022

\section{References}

Accredited Schools Online. (2021). Understanding \& Preventing Plagiarism. Accredited Schools Online. https://www.a ccreditedschoolsonline.org/resources/preventing-plagiarism/

Akbar A, Picard M (2020) Academic integrity in the Muslim world: a conceptual map of challenges of culture. Int J Educ Integr 16(1):1-20. https://doi.org/10.1007/s40979-020-00060-8

Anwar R, Kalra J, Ross M, Smith D, Vogel V (2020) Encouraging Academic Integrity Through a Preventative Framework. Bccampus.ca; Pressbooks. https://pressbooks.bccampus.ca/encourageacademicintegrity/

Bacha NN, Bahous R, Nabhani M (2012) High schoolers' views on academic integrity. Res Pap Educ 27(3):365-381. https://doi. org/10.1080/02671522.2010.550010

Beaudry R (2019) Library learning commons literacies. Can School Libr J 3(2) https://journal.canadianschoollibraries.ca/librarylearning-commons-literacies/

Benjes-Small, C., Ackerman, E., \& Tapp, K. (2008). Exploring the Librarian's Role in Promoting Academic Integrity on Campus. https://commons.emich.edu/cgi/viewcontent.cgi?article=1025\&context=loexconf2006

Blair A (2017) Becoming culturally responsive: reflections from an autoethnographic exploration of teaching and learning English in Brazil. In: Culturally responsive pedagogy. Palgrave Macmillan, Cham, pp 99-119. https://doi.org/10.1007/ 978-3-319-46328-5_5

Broeckelman-Post MA. (2009). Building a culture of academic integrity: the role of communication in creating and changing understandings and enactments of academic integrity. Doctoral dissertation, Ohio University. https://etd.ohiolink.edu/ !etd.send_file?accession=ohiou1242313551\&disposition=inline

Buchansky H (2021) Connections beyond campus: Ontario University library outreach programs for high schools. Partnership: Can J Libr Inf Pract Res 16(1):1-24. https://doi.org/10.21083/partnership.v16i1.5770

Bucher KT (2000) The importance of information literacy skills in the middle school curriculum. Clear House 73(4):217-220. https://www.jstor.org/stable/30189549. https://doi.org/10.1080/00098650009600955

Burhanna K, Jensen M (2006) Collaborations for success: high school to college transitions. Ref Serv Rev 34(4):509-519. https://doi.org/10.1108/00907320610716413 
Cameron L, Montgomery L, Bauer A, Anderson K, Filippelli C (2019) Spectrum of value: State University Libraries supporting K-12 teachers. Libr Acad 19(4):565-575. https://doi.org/10.1353/pla.2019.0035

Campbell A. (2017). Cultural differences in plagiarism. Turnitin.com; turnitin. https://www.turnitin.com/amp/articles/culturaldifferences-in-plagiarism

Carr JA, Rockman IF (2003) Information-literacy collaboration: a shared responsibility. Am Libr 34(8):52-54 https://www.jstor. org/stable/pdf/25648877.pdf

Çelik Ö, Lancaster T (2021) Violations of and threats to academic integrity in online English language teaching. The Literacy Trek 7(1):34-54. https://doi.org/10.47216/literacytrek.932316

Creswell JW (2003) Research design: qualitative, quantitative, and mixed methods approaches, 2nd edn. Sage Publications, Thousand Oaks, Calif

Cutri J, Abraham A, Karlina Y, Patel SV, Moharami M, Zeng S, Manzari E, Pretorius L (2021) Academic integrity at doctoral level: the influence of the imposter phenomenon and cultural differences on academic writing. Int J Educ Integr 17(1):1-16. https://doi.org/10.1007/s40979-021-00074-w

Davies M (2012) A study of post-primary teacher and librarian collaboration in Northern Ireland. University of Ulster, MSc Thesis

Denisova-Schmidt E (2019) What can universities do to stop students cheating? University World News. https://www. universityworldnews.com/post.php?story=20190415143459825

Dukes DL (2012) "It's not cheating if you Don't get caught": critical discourse analysis of academic integrity policies in public high schools. Doctoral dissertation, The George Washington University https://www.proquest.com/openview/1f0377772 d3503ac043096512cd5712e/1?pq-origsite=gscholar\&cbl=18750

Eaton SE. (2019). Exploring the notion of academic integrity literacy. Learning, Teaching and Leadership: A Blog for Educators, Researchers and Other Thinkers. https://drsaraheaton.wordpress.com/2019/03/16/exploring-the-notion-of-academicintegrity-literacy/

Eaton SE (2020) Understanding academic integrity from a teaching and learning perspective: engaging with the 4M framework. Werklund School of Education, University of Calgary, pp 1-4 http://hdl.handle.net/1880/112435

Eaton SE (2021) Academic integrity and literacy. In: Hunt L, Chalmers D (Eds.), University Teaching in Focus. Routledge. pp 163-178. https://doi.org/10.4324/9781003008330-9, https://www.taylorfrancis.com/chapters/edit/10.4324/97810030083309/academic-integrity-literacy-sarah-elaine-eaton

European Network for Academic Integrity. (2018). Academic integrity. Academicintegrity.eu. https://www.academicintegrity. eu/wp/glossary/academic-integrity/

Farmer LSJ, Phamle S (2021) Transitioning to college: impact of high school librarians. J Acad Librariansh 47(1):102262. https://doi.org/10.1016/j.acalib.2020.102262

Foo S, Majid S, Mokhtar IA, Zhang X, Chang YK, Luyt B, Theng YL (2014) Information literacy skills of secondary school students in Singapore. Aslib J Inf Manag 66(1):54-76. https://doi.org/10.1108/AJIM-08-2012-0066

Gavigan KW. (2021). Librarians help students navigate an age of misinformation - but schools are cutting their numbers. The Conversation. https://theconversation.com/librarians-help-students-navigate-an-age-of-misinformation-but-schools-arecutting-their-numbers-168637

Gravett K, Kinchin IM (2020) Referencing and empowerment: exploring barriers to agency in the higher education student experience. Teach High Educ 25(1):84-97. https://doi.org/10.1080/13562517.2018.1541883

Greene JC, Caracelli VJ, Graham WF (1989) Toward a conceptual framework for mixed-method evaluation designs. Educ Eval Policy Anal 11(3):255-274. https://doi.org/10.2307/1163620

Harding TS, Passow HJ, Carpenter DD, Finell CJ (2004) An examination of the relationship between academic dishonesty and professional behavior. IEEE Antennas Propag Mag 46(5):133-138. https://doi.org/10.1109/FIE.2003.1265933

Hongwei Y, Glanzer PL, Johnson BR, Sriram R, Moore B (2017) The association between religion and self-reported academic honesty among college students. J Beliefs Values 38(1):63-76. https://doi.org/10.1080/13617672.2016.1207410e

Hossain Z (2019) Status of secondary school libraries and librarians in Bangladesh. IFLA J 45(2):157-167. https://doi.org/10.11 $77 / 0340035219842317$

Hossain Z (2020) From policy to practice: what do literature, standards and guidelines inform us about the role of schoo libraries and librarians' in cultivating an academic integrity culture? Synergy 18(1) https://slav.vic.edu.au/index.php/ Synergy/article/view/373

Hossain Z (2021) Academic integrity literacy of students at the time of enrollment in postsecondary courses: a study of an online university. In: European conference on academic integrity and plagiarism 2021, pp 33-37 https://aca demicintegrity.eu/conference/proceedings/2021/book_of_abstracts2021.pdf\#page=33

Hulsart R, McCarthy V (2009) Educators' role in promoting academic integrity. Acad Educ Leadersh J 13(4):49 https://www.aba cademies.org/articles/aeljvol13no42009.pdf

International Baccalaureate Organization (IBO). (2019). Academic integrity. https://www.ibo.org/contentassets/76d2b6d4731 f44ff800d0d06d371a892/academic-integrity-policy-english.pdf

International Center for Academic Integrity [ICAI] (2021) The Fundamental Values of Academic Integrity, 3rd edn www.aca demicintegrity.org/the-fundamental-valuesof-academic-integrity

Johnson RB, Onwuegbuzie AJ, Turner LA (2007) Toward a definition of mixed methods research. J Mixed Methods Res 1(2): 112-133. https://doi.org/10.1177/1558689806298224

Kammer J, Hays L (2021) Coding in school Libraries: considering an ethical approach. Educ Libr 44. https://doi.org/10.26443/ el.v44i1.366

Khan ZR, Mulani V (2020) Contract cheating values in school assessments - what values are we really teaching our young students? In: 6th International Conference Plagiarism Across Europe and Beyond 2020, European Network for Academic Integrity, April 17-19, 2020. University of Wollongong in Dubai, UAE

King AE, Brigham SM (2018) Understanding the influence of high school preparation on the success strategies of Canadian University students. Stud Health Technol Inf 256:503-513 https://europepmc.org/article/med/30371410

Mackay R. (2021). Academic integrity is not plagiarism. Monash University Learning and Teaching. https://www.monash.edu/ learning-teaching/insights-and-events/blog/academic-integrity-is-not-plagiarism 
Martin CM, Garcia EP, McPhee M (2012) Information literacy outreach: building a high school program at California State University Northridge. Educ Libr 35(1-2):34-47

McKeever C, Bates J, Reilly J (2017) School library staff perspectives on teacher information literacy and collaboration. J Inf Lit 11(2). https://doi.org/10.11645/11.2.2187

Menéndez MPM, Valle JM (2018) Academic honesty in K-12 education: the case of the international baccalaureate. J Supranational Policies Educ 7:24-37 https://repositorio.uam.es/bitstream/handle/10486/684366/JOSPOE-7_4. pdf?sequence $=1$

Miller C, Bartlett J (2012) Digital fluency': towards young people's critical use of the internet. J Inf Lit 6(2):35-55. https://doi. org/10.11645/6.2.1714

Morrow L (2018) Academic integrity outreach: supporting high school students for success in higher education. Can Perspect Acad Integr 1(1):6-8. https://doi.org/10.11575/cpai.v1i1.43375

Mulisa F, Ebessa AD (2021) The carryover effects of college dishonesty on the professional workplace dishonest behaviors: a systematic review. Cogent Educ 8(1) https://www.tandfonline.com/doi/pdf/10.1080/2331186X.2021.1935408

Nawaz S. (2017). English Language Teachers' perceptions of academic integrity and classroom behaviour of culturally diverse adult English Language Learners (ELLs) in Canada: A critical perspective. http://hdl.handle.net/10871/31176

Nelson MF, James MS, Miles A, Morrell DL, Sledge S (2017) Academic integrity of millennials: the impact of religion and spirituality. Ethics Behav 27(5):385-400 https://www.tandfonline.com/doi/abs/10.1080/10508422.2016.1158653

Newton P (2016) Academic integrity: a quantitative study of confidence and understanding in students at the start of their higher education. Assess Eval High Educ 41(3):482-497. https://doi.org/10.1080/02602938.2015.1024199

Ngo H, Walton G (2016) Examining the practice of information literacy teaching and learning in Vietnamese upper secondary schools. Educ Inf 32(3):291-303. https://doi.org/10.3233/EFI-160978

Nichols J, Spang L, Padron K (2005) Building a Foundation for Collaboration. Resour Shar Inf Netw 18(1-2):5-12. https://doi. org/10.1300/J121v18n01_02

Orosz G, Tóth-Király I, Bőthe B, Kusztor A, Kovács ZÜ, Jánvári M (2015) Teacher enthusiasm: a potential cure of academic cheating. Front Psychol 6:318. https://doi.org/10.3389/fpsyg.2015.00318

Samanta, A. (2018). ICT and academic integrity at secondary level. NSOU Open J, 1(1). http://www.wbnsou.ac.in/openjournals/ Issue/1st-Issue/ICT\%20and\%20Academic\%20Integrity\%20at\%20Secondary\%20Level.pdf

Saunders L, Severyn J, Caron J (2017) Don't they teach that in high school? Examining the high school to college information literacy gap. Libr Inf Sci Res 39(4):276-283. https://doi.org/10.1016/j.lisr.2017.11.006

Shephard K (2015) Values Education for Sustainability, Academic Integrity and Professional Values. In: Higher Education for Sustainable Development. Palgrave Pivot, London. https://doi.org/10.1057/9781137548412_6

Schoonenboom J, Johnson RB (2017) How to construct a mixed methods research design. Köln Z Soziol 69(2):107-131. https://doi.org/10.1007/s11577-017-0454-1

Smith LN (2016) School libraries, political information and information literacy provision: findings from a Scottish study. J Inf Lit 10(2):3-25. https://doi.org/10.11645/10.2.2097

Stoesz BM, Yudintseva A (2018) Effectiveness of tutorials for promoting educational integrity: a synthesis paper. Int J Educ Integr 14(1):6. https://doi.org/10.1007/s40979-018-0030-0

Tauginienè L., \& Gaižauskaitè, I. (2018). Integrity Management in High Schools: paving a way to misconduct? Towards consistency and transparency in academic integrity/editors: Salim Razı, Irene Glendinning, Tomáš Foltýnek, 105-116. https://www.lituanistika.lt/content/83513

Thompson LW, Bagby JH, Sulak TN, Sheets J, Trepinski TM (2017) The cultural elements of academic honesty. J Int Stud 7(1): $136-153$

Velliaris DM, Breen P (2016) An institutional three-stage framework: elevating academic writing and integrity standards of international pathway students. J Int Stud 6(2):565-587. https://doi.org/10.32674/jis.v6i2.371

Venezia A, Jaeger L (2013) Transitions from high school to college. Futur Child 23(1):117-136. https://www.jstor.org/sta ble/23409491. https://doi.org/10.1353/foc.2013.0004

Vieyra M, Weaver K (2016) The prevalence and quality of source attribution in middle and high school science papers. Issues Sci Technol Librariansh 83:13 http://istl.org/16-winter/refereed2.html

Wagg S, McKinney P (2020) Information literacy outreach between universities and schools: a case study. J Inf Lit 14(2). https://doi.org/10.11645/14.2.2692

Williamson K, McGregor J (2011) Generating knowledge and avoiding plagiarism: smart information use by high school students. School Libr Media Res 14 https://files.eric.ed.gov/fulltext/EJ954598.pdf

Yoannou A (2014) Academic integrity: perceptions and practices in secondary school humanities classes. Master of Teaching Research Projects, University of Toronto http://hdl.handle.net/1807/67070

\section{Publisher's Note}

Springer Nature remains neutral with regard to jurisdictional claims in published maps and institutional affiliations.

Ready to submit your research? Choose BMC and benefit from:

- fast, convenient online submission

- thorough peer review by experienced researchers in your field

- rapid publication on acceptance

- support for research data, including large and complex data types

- gold Open Access which fosters wider collaboration and increased citations

- maximum visibility for your research: over $100 \mathrm{M}$ website views per year

At $\mathrm{BMC}$, research is always in progress.

Learn more biomedcentral.com/submissions 